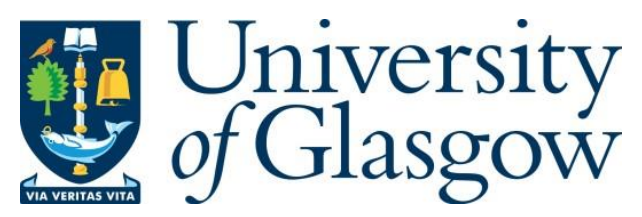

Kelp, C. (2009) Pritchard on virtue epistemology. International Journal of Philosophical Studies, 17(4), pp. 583-587.

There may be differences between this version and the published version. You are advised to consult the publisher's version if you wish to cite from it.

$\underline{\text { http://eprints.gla.ac.uk/140929/ }}$

Deposited on: 15 May 2017

Enlighten - Research publications by members of the University of Glasgow http://eprints.gla.ac.uk 


\title{
Pritchard on Virtue Epistemology
}

\author{
Christoph Kelp*
}

\begin{abstract}
Duncan Pritchard has recently argued against robust virtue epistemology on the grounds that it gets caught up in a fatal double bind: There is a type of case suggesting that the central robust virtue theoretic condition on knowledge is too strong to be necessary for knowledge as well as a type of case suggesting that it is too weak to be sufficient for knowledge. He does concede to the robust virtue epistemologist that his argument will be fully convincing only if it really is a double bind the view gets caught up in, i.e. if robust virtue epistemology faces both types of case. This paper shows that Pritchard's argument fails to fulfil its promise. I consider the two major ways of interpreting the virtue theoretic condition and argue that while it is plausible that for each interpretation of this condition one problematic type of case arises, for neither interpretation both problematic types of case arise. In consequence, by his own lights, Pritchard's argument turns out unconvincing.
\end{abstract}

\section{Pritchard's Argument}

In a number of recent papers Duncan Pritchard has launched a highly infuential attack on a view that he calls robust virtue epistemology (RVE). ${ }^{1}$ The central thesis of RVE is the following:

${ }^{*}$ Centre for Logic and Analytic Philosophy, University of Leuven, Kardinaal Mercierplein 2, 3000 Leuven, Belgium 
(RVECT) One knows that $p$ iff the truth of one's belief that $p$-alternatively, one's cognitive success-is because of the exercise of cognitive ability.

If it can be made to work, RVE will be a very powerful theory of knowledge. It promises to provide the key to the solution of a number of pressing problems in epistemology such as the Gettier problem and the problem of the value of knowledge. $^{2}$

However, Pritchard argues that RVE is not viable. More specifically, Pritchard adduces two types of case in the first one of which, intuitively, the subject has knowledge but does not attain cognitive success because of the exercise of cognitive ability, whilst in the second one the subject attains success because of ability but, intuitively, does not know. Notice that Pritchard admits that on its own each type of case would not be enough to make a fully convincing case against RVE. After all, if the only problem RVE faces were that there is a type of case in which the subject attains success because of ability but intuitively doesn't know (doesn't attain success because of ability but intuitively knows), the defender of RVE "might reasonably take the heroic route of denying the intuition in this [type of] case" [Pritchard Forthcomingb, 10]. ${ }^{3}$ However, if RVECT fails to predict in accordance with intuition in both types of case there is strong reason to believe that something is fundamentally wrong with RVE. After all, combined the two types of case would pull the defender of RVE in opposite directions-one type of case suggesting that RVECT is too strong to be necessary, the other that it is too weak to be sufficient for knowledge.

\section{$2 \quad$... Fails to Convince}

In what follows, I will provide reason to believe that Pritchard's argument fails to show that RVE is caught up in the double bind that would seal the case against the view. If so, then, by his own lights, Pritchard's argument against 
RVE fails to be fully convincing.

Let's start by looking at Pritchard's central cases. The first case is the infamous case of Henry in Fake Barn County. Looking out of the window whilst driving along the road, Henry sees what happens to be the only real barn in a field otherwise full of fake barns and forms a belief that he is looking at a barn. Plausibly, Henry's cognitive success is because of the exercise of his ability to spot barns. This point can be further reinforced by considering the following case: Archie is shooting at the only normal target at a range otherwise full of targets fitted with forcefields that would repel any shot fired at them. When Archie, who is a skilled archer, exercises his arching ability and hits the target right in the centre, certainly his athletic success is due to his arching ability. But now notice that the case of Archie is formally analogous to the case of Henry with the only normal target at the range taking the place of the only real barn in the field and the forcefield targets taking the place of the fake barns. Given that the two cases are analogous, if Archie attains (athletic) success because of his arching skill, it is plausible that Henry also attains (cognitive) success because of his barn-spotting ability. At the same time, intuitively, Henry's belief that he is looking at a barn does not qualify as knowledge. So we now have a case in which the subject attains cognitive success because of the exercise of cognitive ability but intuitively does not know.

In Pritchard's second case the protagonist, Jenny, arrives in an unknown city and asks the first passerby she encounters for directions to a famous landmark. Her informant is a knowledgeable resident of the city who provides her with impeccable directions. Intuitively, the beliefs about how to get to the landmark Jenny forms on the basis of her informant's testimony qualify as knowledge. However, it would seem that in this case Jenny does not attain cognitive success because of the exercise of cognitive ability. If anything, her success is due to 
her informant's ability. So, we also have a case in which the subject intuitively has knowledge but does not attain cognitive success because of the exercise of cognitive ability.

In order to see why Pritchard's argument fails to show that RVE gets caught up in the fatal double bind I would like to take a closer look at the term 'because of' that RVECT features. There are two major proposals as to how this term is to be interpreted. The first one is due to John Greco [Greco 2003]. He claims that success is because of the exercise of ability if the exercise of ability best explains the success. As opposed to that, the second proposal, due to Ernest Sosa [Sosa 2007], has it that success is because of the exercise of ability if the success manifests ability. As I am about to show, on each of these interpretations of 'because of', RVECT will be unable to analyse one of Pritchard's types of case in accordance with intuition but on neither of them RVECT will be unable to do so for both. Thus, we will see not only that there are some interpretations of RVECT that will avoid the double bind that, according to Pritchard, is fatal for RVE but also that on none of the major interpretations of RVECT, RVE actually is caught up in it.

Let's first consider Greco's interpretation of 'because of'. Is it plausible that in Jenny's case, her cognitive success is best explained by the exercise of cognitive ability? It seems that the answer to this question is 'no'. After all, it is plausible that what best explains Jenny's cognitive success is the fact that her informant is as knowledgeable about the city as he is. So, on this interpretation of 'because of', RVECT will be unable to analyse cases of this type in accordance with intuition. But what about the case of Henry: Is it plausible that his cognitive success is best explained by the exercise of his barn-spotting ability? Certainly not: In Fake Barn County what best explains his cognitive success is the fact that he happens to look at the only real barn in a field otherwise 
full of fakes. ${ }^{4}$ So, RVECT will predict in accordance with intuition in this case. Pritchard's argument fails to show that, on Greco's interpretation of 'because of', RVE is caught up in the fatal double bind.

As regards Sosa's interpretation of 'because of' things are exactly the other way around. It is plausible that Henry's cognitive success is because of the exercise of his barn-spotting ability if 'because of' is interpreted in Sosa's way. After all, Henry is brought into cognitive contact with the fact that he is looking at a barn through the exercise of his barn-spotting ability. In this way, his barn-spotting ability seems to be manifest in his cognitive success. So, RVECT, interpreted in Sosa's way, fails to predict in accordance with intuition in this type of case. However, it is far from clear that in the case of Jenny, her cognitive success does not manifest cognitive ability. As Pritchard himself notices, Jenny exhibits "quite a lot of cognitive ability if one examines the case a little more closely." [Pritchard Forthcomingb, 9] For instance, Pritchard points out that Jenny would not just have asked anyone-she wouldn't have asked a dog, a lamp post, a child etc.-and she would not have believed just anything-she would have spotted obviously false directions as such etc. Moreover, it is plausible that Jenny also exercises cognitive abilities requisite to interpret her informant's speech act with respect to propositional content-that she has to walk down Fleet Street, not Elm Street, for instance-as well as force-that it was a speech act of informing her that she has to walk down Fleet Street rather than advising her to go there to get further information, say. Once one spells out Jenny's cognitive involvement in more detail, however, even if it remains true that her cognitive success is not best explained by the exercise of these cognitive abilities, it becomes more and more plausible that her cognitive success does manifest cognitive ability in the sense required by Sosa's interpretation of 'because of'. If this is correct, RVECT, interpreted in Sosa's way, will predict in accordance 
with intuition in this type of case.

We thus see that on neither of the two major interpretations of the term 'because of' at issue in RVECT that can be found in the literature, RVE gets caught up in the double bind that Pritchard regards as fatal for the view. In consequence, by his own lights, Pritchard has failed to make a convincing case against RVE. Of course, it remains to be shown which interpretation of RVECT the defender of RVE should go for. But whether it be Greco's or Sosa's or perhaps yet a different one, what is of importance is that RVE does remain a live option in the theory of knowledge.

\section{References}

[Greco 2003] Greco, J. 2003. 'Knowledge as Credit for True Belief' in DePaul, M. and Zagzebski, L. (eds.) Intellectual Virtue: Perspectives from Ethics and Epistemology. Oxford: OUP.

[Greco Forthcoming] Greco, J. Forthcoming. 'The Value Problem' in Haddock, A., Millar, A. and Pritchard D. (eds.) The Value of Knowledge, Oxford: OUP.

[Pritchard 2007a] Pritchard, D. 2007a. 'The Value of Knowledge' in Zalta, E. (ed.), Stanford Encyclopedia of Philosophy.

[Pritchard 2007b] Pritchard, D. 2007b. 'Recent Work on Epistemic Value' in American Philosophical Quarterly 44: 85-110.

[Pritchard 2008a] Pritchard, D. 2008a. 'Greco on Knowledge: Virtues, Contexts, Achievements' in The Philosophical Quarterly 58: 43747. 
[Pritchard 2008b] Pritchard, D. 2008b. 'Radical Scepticism, Epistemic Luck and Epistemic Value' in Proceedings and Addresses of the Aristotelian Society (suppl. vol.) 82: 19-41.

[Pritchard 2008c] Pritchard, D. 2008c. 'Knowledge and Final Value' in Haddock, A., Millar, A. and Pritchard, D., The Value of Knowledge, manuscript.

[Pritchard Forthcominga] Pritchard, D. Forthcominga. 'Apt Performance and Epistemic Value' in Philosophical Studies.

[Pritchard Forthcomingb] Pritchard, D. Forthcomingb. 'Knowledge, Understanding and Epistemic Value' in Think.

[Pritchard Forthcomingc] Pritchard, D. Forthcomingc. Knowledge. New York: Palgrave Macmillan.

[Sosa 1991] Sosa, E. 1991. Knowledge in Perspective: Selected Essays in Epistemology. Cambridge: CUP.

[Sosa 2007] Sosa, E. 2007. A Virtue Epistemology. Apt Belief and Reflective Knowledge, Volume 1. Oxford: Oxford University Press.

[Zagzebski 1996] Zagzebski, L. 1996. Virtues of the Mind: An Inquiry into the Nature of Virtue and the Ethical Foundations of Knowledge. Cambridge: CUP.

\section{Notes}

${ }^{1}$ See for instance [Pritchard 2007a], [Pritchard 2007b], [Pritchard 2008a], [Pritchard 2008b], [Pritchard 2008c], [Pritchard Forthcominga], [Pritchard Forthcomingb], [Pritchard Forthcomingc].

${ }^{2}$ For RVE and the Gettier problem see e.g. [Sosa 1991], [Greco 2003] and [Zagzebski 1996]. For RVE and the value of knowledge see e.g. [Greco Forthcoming] and [Pritchard 2008a]. 
${ }^{3}$ It is worth noting that this point can be reinforced by Pritchard's own argument that if RVE turns out to not to be viable, we will have to make provision for some radical revisions in the theory of knowledge (most notably with respect to the putative value of knowledge-see e.g. [Pritchard 2007a, §4] and [Pritchard 2008c]). Unless we have strong reason to believe that RVE is fundamentally flawed, we might well opt for holding on to RVE even at the expense of some pre-theoretical intuitions.

${ }^{4}$ Notice that Pritchard sometimes claims that Henry's cognitive success is best explained by the exercise of his barn-spotting ability (e.g. in [Pritchard Forthcomingc, 47]). That, however, just doesn't seem right. Perhaps Pritchard is driven to this claim by an intuition that in Archie's case, the corresponding athletic success is best explained by Archie's arching ability. Even so, it seems that intuition speaks strongly against the idea that Henry's cognitive success is best explained by his barn-spotting ability. If intuition gives a different verdict in the case of Archie, a defender of RVE could exploit this fact to his advantage to argue that, contrary to first appearances, perhaps the two cases aren't analogous after all. 